Aim(s)/objectives To audit occupational PEP/PEPSE related attendances in a sexual health clinic (SHC) in 2015 and compare to a previous audit (2011-2013).

Methods A retrospective case note review of patients attending in 2015 for PEP/PEPSE. Clinical records were unavailable for patients attending prior to April 2015 due to the SHC contract transferring to a new provider.

Results A total of 8 patients attended for PEPSE, two were initiated in A\&E, 1 in a Sexual Assault Referral Centre (SARC) and 4 in the SHC. All patients attended after sexual exposure, with none attending after needle stick injury. All patients were started on PEPSE within 72 hours, had baseline HIV test and STI screen. All had PEPSE prescribed within the recommended indications compared to $88 \%$ previously. Fifty percent finished PEP course whilst $25 \%$ had a documented HIV test 4-6 weeks post PEP.

Discussion/conclusion Issues around clinical record ownership have been interpreted differently across trusts. Locally, when the provider for the SHC changed, minimal patient record information was transferred to the new trust. This limited access contributed to small audit numbers. Compared to previous audit smaller numbers of patients finished the PEP course and attended for follow up HIV test but clinicians have a greater understanding of recommended indications for PEPSE.

\section{P045 SWITCHING FROM BOOSTED ATAZANAVIR (ATV) PLUS FTC/TDF TO A TAF-BASED SINGLE TABLET REGIMEN (STR): WEEK 48 DATA IN VIROLOGICALLY SUPPRESSED ADULTS}

${ }^{1}$ Chloe Orkin* ${ }^{2}$ Bart Rijnders, ${ }^{3}$ Christoph Stephan, ${ }^{4}$ Mehri Mckellar, ${ }^{5}$ Sasisopin Kiertiburanakul, ${ }^{6}$ Jose Arribas, ${ }^{7}$ Daniel Murphy, ${ }^{8}$ Mark Bloch, ${ }^{9}$ YaPei Liu, ${ }^{10}$ Marshall Fordyce, ${ }^{11}$ Stuart Yau, ${ }^{10}$ Scott McCallister. ${ }^{1}$ Barts and The London NHS Trust, London, UK; ${ }^{2}$ Erasmus MC, Internal Medicine and Infectious Diseases, Rotterdam, The Netherlands; ${ }^{3}$ Universitats Klinikum Frankfurt, Frankfurt, Germany; ${ }^{4}$ Duke University, Durham, USA; ${ }^{5}$ Ramathibodi Hospital, Bangkok, Thailand; ${ }^{6}$ Hospital Universitario La Paz, IdiPAZ, Madrid, Spain; ${ }^{7}$ Clinique Médicale l'Actuel, Montreal, Canada; ${ }^{8}$ Holdsworth House Research, Sydney, Australia; ${ }^{9}$ Gilead Sciences, Inc., Biometrics, Foster City, USA; ${ }^{10}$ Gilead Sciences, Inc., Clinical Research, Foster City, USA; ${ }^{11}$ Gilead Sciences Ltd, High Holborn, London, UK

\subsection{6/sextrans-2016-052718.99}

Background/introduction Tenofovir alafenamide (TAF) is a tenofovir prodrug that contains elvitegravir $150 \mathrm{mg} /$ cobicistat $150 \mathrm{mg} /$ FTC 200mg/TAF 10mg (E/C/F/TAF).

Aim(s)/objectives This study assessed efficacy and possible bone and renal safety advantages in patients who switched from a TDF-based regimen to $\mathrm{E} / \mathrm{C} / \mathrm{F} / \mathrm{TAF}$.

Methods Virologically suppressed (HIV-1 RNA $<50$ copies/ml) adults on a TDF-based regimen for at least 96 weeks were randomised 2:1 to switch to open label E/C/F/TAF or to continue their prior regimen. At baseline, the median CD4 count was 658 cells/uL, the median eGFR(Cockcroft-Gault) was $103.8 \mathrm{~mL} / \mathrm{min}$ and $10.6 \%$ of patients had baseline proteinuria of at least $1+$ on dipstick analysis.

Results At Week 48, 390/402 (97.0\%) of those who switched to E/C/F/TAF and 183/199 (92.0\%) of those continuing boosted ATV plus FTC/TDF had HIV-1 RNA $<50 \mathrm{c} / \mathrm{mL}$ (difference, 5.1\%; 95\% CI: $0.9 \%$ to $9.2 \%$ ). No patients had virologic failure with resistance. In patients who switched, hip and spine bone mineral density (BMD) improved significantly, and proteinuria and specific tubular proteinuria also improved significantly Serum creatinine mean change $(\mu \mathrm{mol} / \mathrm{L})$ from baseline: $\mathrm{E} / \mathrm{C} / \mathrm{F} /$
TAF, +0.88; ATV+ FTC/TDF, +3.54 ( $\mathrm{p}=0.003) . \mathrm{E} / \mathrm{C} / \mathrm{F} / \mathrm{TAF}$ patients had statistically higher changes from baseline in fasted lipid tests; the median change in total cholesterol: HDL ratio was: $\mathrm{E} / \mathrm{C} / \mathrm{F} / \mathrm{TAF}, \quad+0.2 ;$ boosted $\mathrm{ATV}+\mathrm{FTC} / \mathrm{TDF}, \quad+0.0$ $(\mathrm{p}=0.001)$.

Discussion/conclusion At Week 48, patients who switched from a boosted ATV+FTC/TDF regimen to E/C/F/TAF had a significantly higher rate of virologic control, had significant improvements in hip BMD, spine BMD and in serum creatinine, and also had significantly less proteinuria than those continuing on their TDF-based regimen.

\section{P046 A NEW APPROACH TO QUANTIFYING HEALTH ADVISER INPUT IN A RE-COMMISSIONED SEXUAL HEALTH SERVICE}

Sumit Bhaduri*, Carolyn Gosling. Dept of sexual health, Worcestershire Health and Care Trust, Worcestershire, UK

\subsection{6/sextrans-2016-052718.100}

Background/introduction With sexual health services going out to tender, commissioning intentions have prioritised health promotion and prevention strategies. Whilst these activities are currently performed they have been difficult to quantify. Consequently, new codes have been devised to register face to face and telephone input for a) counselling/support/safeguarding issues face to face (HCSF) b) counselling/support/safeguarding via telephone interaction (HCST), c) Health education/health promotion or advice face to face (HEF) d) Health education/ health promotion or advice via telephone interaction (HET) e) partner notification face to face (HPNF) and e) partner notification via telephone interaction(HPNT)

Aim(s)/objectives To ascertain whether the newly devised codes have been integrated into routine service

Methods Case notes were analysed over a 3 month period to ascertain, the frequency of use of such codes

Results 37 case notes had input as regards counselling/support/ safeguarding face to face (HCSF). 14 had such input via telephone. 75 case notes had input as regards health education/ health promotion (HET) face to face, 94 had such input via telephone. 66 case notes had input as regards partner notification face to face, 43 had this via telephone.

Discussion/conclusion It has been established that the codes have been easy to apply and have already given a quantitative view as regards health promotion/education/safeguarding, which has supported discussions with commissioners. It is envisaged that use of the codes will enable of health adviser interventions to be measured time wise. This work will also be presented.

\section{P047 HEALTH CARE NEEDS OF WOMEN AGED 40 AND OVER ATTENDING AN INNER CITY INTEGRATED SEXUAL HEALTH CLINIC}

1,2Patrice Grech*, ${ }^{1}$ Rebecca Marchant, ${ }^{1,2}$ Mannampallil Samuel. ${ }^{1}$ Camberwell Sexual Health Centre, London, UK; ${ }^{2}$ King's College Hospital, London, UK

\subsection{6/sextrans-2016-052718.101}

Background/introduction Sexual health policy is targeted towards younger adults, with national screening programmes and research studies excluding individuals over the age of 44 . UK surveillance data demonstrated that rates of sexually 